In: Proteases as Targets for Therapy: Handbook of Experimental Pharmacology, Vol. 140, K: von der Helm, B. D. Korant, and

J. C. Cheronis, Editors, Chapter 8, pp. 145-158 and 398-399, Springer-Verlag, Heidelburg, Germany (2000).

\title{
CHAPTER 8 \\ Adenovirus Proteinase-Antiviral Target for Triple-Combination Therapy on a Single Enzyme: Potential Inhibitor-Binding Sites
}

W. F. Mangel, D.L. Toledo, M.T. Brown, J. Ding, R.M. Sweet, D.L. BARNARD, and W.J. MCGRATH

\section{A. Virus-Coded Proteinases as Targets for Antiviral Therapy}

Virus-coded proteinases are attractive targets for antiviral therapy. These enzymes are essential for the synthesis of infectious virus and perform a wide variety of tasks at different times and places during an infection. Among the medically important virus families with members known to encode proteinases (Krausslich and WIMmer 1988; BebÉ and Craig 1997) are: the picornaviruses, which include polio, rhino and hepatitis $A$; the retroviruses, which include human immunodeficiency virus (HIV); the fiaviviruses, which include hepatitis $\mathrm{C}$; the orthomyxoviruses, which include influenza; the herpes viruses, which include cytomegalovirus; and the adenoviruses. Viral proteinases are extremely specific enzymes, and there has been expectation that equally specific inhibitors may be effective antiviral agents. This expectation has recently been realized with the advent of HIV-proteinase inhibitors that have been shown to be extremely specific biochemically and effective clinically.

Human adenovirus presents a good model system to study the exploitation of virus-coded proteinases as targets for antiviral therapy. The adenovirus proteinase contains three potential sites for antiviral therapy - the active site and the sites to which two cofactors, the viral DNA and the 11 amino acid peptide pVIc, bind to activate the enzyme. Thus human adenovirus can be used as a model system to test the hypothesis that the probability of generating a virus resistant to three different inhibitors directed against three different sites on the same virus-coded protein is much lower than to three different inhibitors directed against three different virus-coded proteins.

\section{Adenovirus and Its Proteinase in the Virus Life Cycle}

There are 47 serotypes of adenovirus, and they can cause acute infections of the respiratory and gastrointestinal tracts and of the eye (Horwitz 1990; Hierholzer et al. 1991). Adenovirus is a nonenveloped virus that contains $34,000-36,000$ bp of double-stranded (ds) DNA, with a potential coding capacity for more than 50 proteins (Horwitz 1990; Hierholzer et al. 1991). The human adenovirus proteinase (AVP) is activated late in infection. After formation of empty capsid shells, the viral DNA, along with capsid components, 
enters the shells to form immature virions. The virus-coded proteinase is then activated; it cleaves six virion precursor proteins, thereby rendering the virus particles infectious (Mirza and Weber 1980; Hannan et al. 1983). There are about 50 proteinase molecules per virion (Brown et al. 1996), and they cleave the multiple copies of six different virion precursor proteins 2500 times in each virus particle. AVP may play a role in virus entry into cells (COTTEN and WEBER, 1995; GREBER et al. 1996); inhibition of the viral proteinase blocked the degradation of the capsid-stabilizing protein VI and prevented virus uncoating - and thereby release of the viral DNA - at the nuclear membrane (GreBER et al. 1996).

\section{The AVP as a Model System for Antiviral Agents}

The AVP is an ideal enzyme system within which to test proteinase inhibitors as antiviral agents. A wide range of animals can be infected by different strains of adenovirus, including mice, chickens and monkeys, so that once good inhibitors of the enzyme are found they can be tested as antiviral agents in several animal systems. At a minimum, the AVP utilizes three geographically distinct sites for optimal enzyme activity: an active site and two cofactorbinding sites. These sites have been characterized biochemically, and the crystal structure of the enzyme with one of the cofactors bound is known at resolutions of $2.6 \AA$ (DING et al. 1996) and $1.6 \AA$ (McGrath et al. unpublished observations). Here, we describe these three sites and discuss the design of different types of inhibitors to bind to these sites and function as antiviral agents. We also address the issue of resistance and how this enzyme system may be used to study the efficacy of different variations of combination therapy.

\section{B. Biochemistry of the AVP}

\section{Cloning of the Gene and Development of an Assay for the Adenovirus-2 Proteinase}

The gene for the AVP has been identified (YEH-KAI et al. 1983), cloned and expressed in Escherichia coli (ANDERSON 1993), and the resultant 204-aminoacid protein purified (Mangel et al. 1993; Tihanyi et al. 1993; Webster et al. 1993; MANGEL et. al. 1996). The enzyme was shown to be highly specific; analysis by WEBSTER et al. (1989a, b) of the cleavage sites in the six virion precursor proteins processed by AVP indicated requirements of either Leu, Ile or Met in the P4 position and Gly in the P2, followed by Gly-Xxx or Xxx-Gly. In this notation (SCHECHTER and BERGER 1967), P1 is the amino acid in a substrate that is cleaved at its $\mathrm{C}$-terminus and $\mathrm{P} 2$ is the adjacent amino acid $\mathrm{N}$-terminal to P1 (SChechter and Berger 1967). Xxx is any amino acid residue. We synthesized (Leu-Arg-Gly-Gly-NH) ${ }_{2}$-rhodamine and showed it to be an extremely specific, sensitive and selective substrate for AVP within disrupted 
wild-type adenovirus serotype 2 (Ad2) virions (MANGel et al. 1993; MCGRath et al. 1996). However, purified recombinant AVP exhibited no proteinase activity (MANGel et al. 1993; Webster et al. 1993; MANGel et al. 1996). Eventually, cofactors were discovered.

\section{Discovery and Characterization of Two Cofactors}

One cofactor is the viral DNA (MANGel et al. 1993). If disrupted wild-type Ad2 virus is treated with DNase and then assayed, proteinase activity is lost but can be restored upon addition of Ad2 DNA. A second cofactor is a plasmin-sensitive virion protein, which turned out to be the 11-amino-acid peptide, pVIc, from the C-terminus of the precursor to virion protein VI (MANGEL et al. 1993; WeBsTER et al. 1993). Its sequence is GVQSLKRRRCF.

The cofactors affect the macroscopic kinetic constants of the interaction of AVP with the rhodamine-based fluorogenic substrates (MANGEL et al. 1996). AVP alone has a small amount of activity. By incubating Ad2 DNA with AVP, the Michaelis constant $\left(K_{\mathrm{m}}\right)$ increases twofold and the catalytic rate constant $\left(k_{\text {cat }}\right)$ threefold. By incubating pVIc with AVP, $K_{\mathrm{m}}$ increases twofold and $k_{\text {cat }}$ increases 350-fold. With all three components together, AVP plus Ad2 DNA plus pVIc, $K_{\mathrm{m}}$ increases twofold and $k_{\mathrm{cat}}$ increases 6000 -fold relative to those with AVP alone. Thus, the cofactors increase proteinase activity by increasing the $k_{\text {cat }}$, not decreasing the $K_{\mathrm{m}}$.

\section{Binding Interactions among the Cofactors}

\section{AVP Binding to pVIc in the Absence and Presence of DNA}

The binding interactions among the cofactors were characterized by titration curves and by fluorescence polarization. For the interaction of AVP with pVIc, we incubated a constant amount of AVP with increasing amounts of pVIc and assayed for enzyme activity. When the amount of enzyme activity was plotted on the ordinate versus the concentration of pVIc, a hyperbola was obtained. If one assumes that at the plateau all the AVP had been titrated with pVIc, then the data could be transformed into bound pVIc versus free pVIc (Fig 1A) and, from this, an equilibrium dissociation constant $\left(K_{d}\right)$ of $682 \pm 121 \mathrm{nM}$ could be calculated. When this titration was repeated in the presence of an excess of T7 DNA, and with AVP varied as opposed to pVIc, the $K_{\mathrm{d}}$ dropped to $54.7 \pm 0.6 \mathrm{nM}$ (Fig. 1B).

\section{AVP-pVIc-Complex Binding to DNA}

In order to characterize the interaction of AVP-pVIc complexes with DNA, we titrated a constant amount of ds 36-mer DNA with increasing amounts of AVP-pVIc compleses and assayed for enzyme activity (Fig. 2). Here, tight binding, characterized by two straight lines, was observed; below saturation, 

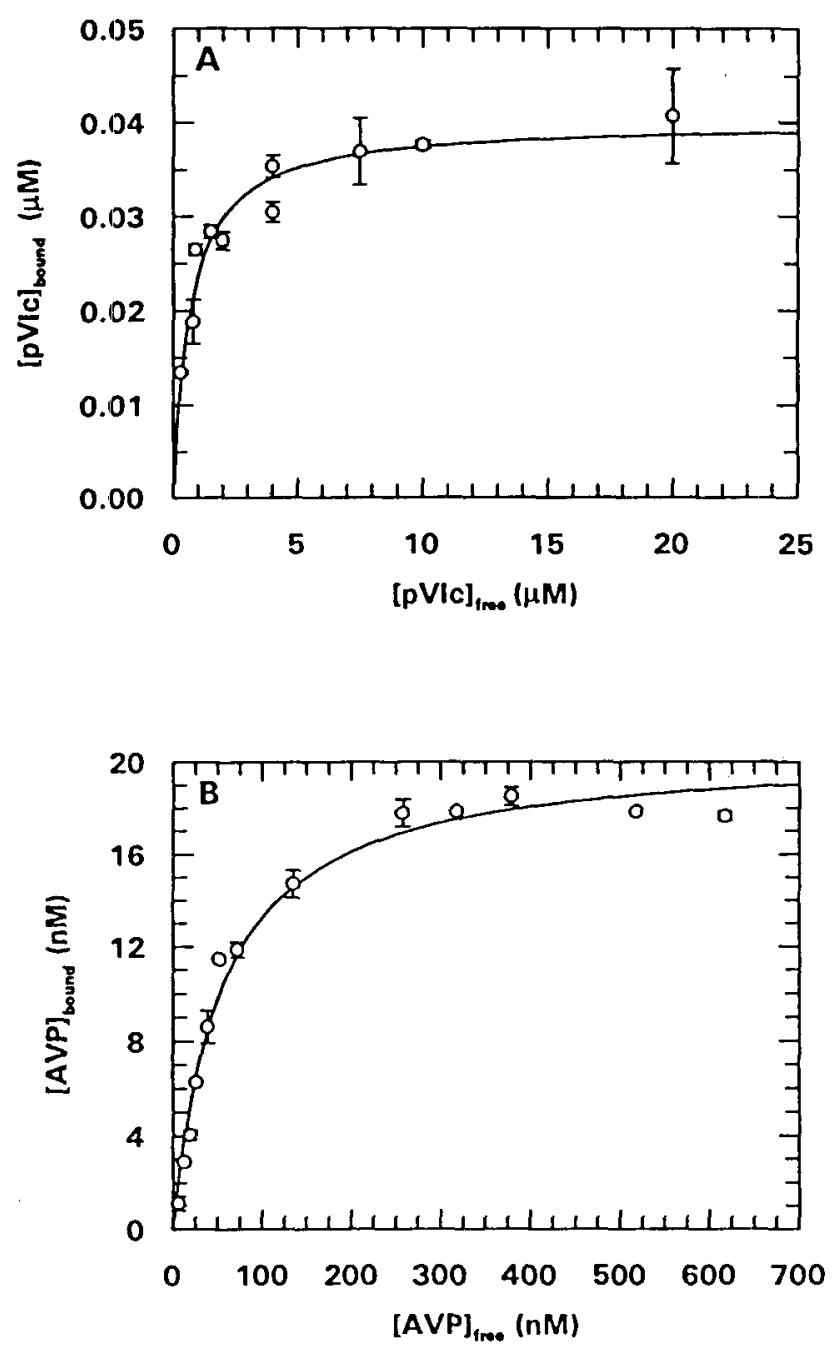

Fig. 1A,B. Binding of pVIc to adenovirus proteinase (AVP) in the absence (A) and presence (B) of DNA. A Reactions $(1 \mathrm{ml})$ that contained $0.01 \mathrm{M}$ tris(hydroxymethyl)aminomethane (Tris, pH 8.0), $5 \mathrm{mM}$ octylglucoside, $40 \mathrm{nM}$ AVP and concentrations of pVIc that ranged from $0-20 \mu \mathrm{M}$ were incubated at $37^{\circ} \mathrm{C}$ for $5 \mathrm{~min}$. Then

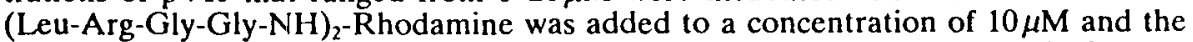
increase in fluorescence was monitored as a function of time. The change in fluorescence was calculated by subtracting the fluorescence of the sample without $p$ VIc from the fluorescence of samples containing pVIc. The change in fluorescence was plotted versus time and the resulting rates were transformed to concentrations of bound and free pVIc. B Reactions $(1 \mathrm{ml})$ that contained $0.01 \mathrm{M}$ Tris $(\mathrm{pH} 8.0), 5 \mathrm{mM}$ octylglucoside, $1.5 \mu \mathrm{g} / \mathrm{ml}$ T7 DNA, $20 \mathrm{nM}$ pVIc and concentrations of AVP that ranged from $0-600 \mathrm{nM}$ were incubated at $37^{\circ} \mathrm{C}$ for $3 \mathrm{~min}$. Then (Leu-Arg-Gly-Gly-NH) ${ }_{2}$-Rhodamine was added to a concentration of $2 \mu \mathrm{M}$ and the increase in fluorescence was monitored as a function of time. The change in fluorescence was calculated by subtracting the fluorescence of the sample without AVP from the fluorescence of samples containing AVP. The change in fluorescence was plotted against time and the resulting rates transformed to concentrations of bound and free AVP 


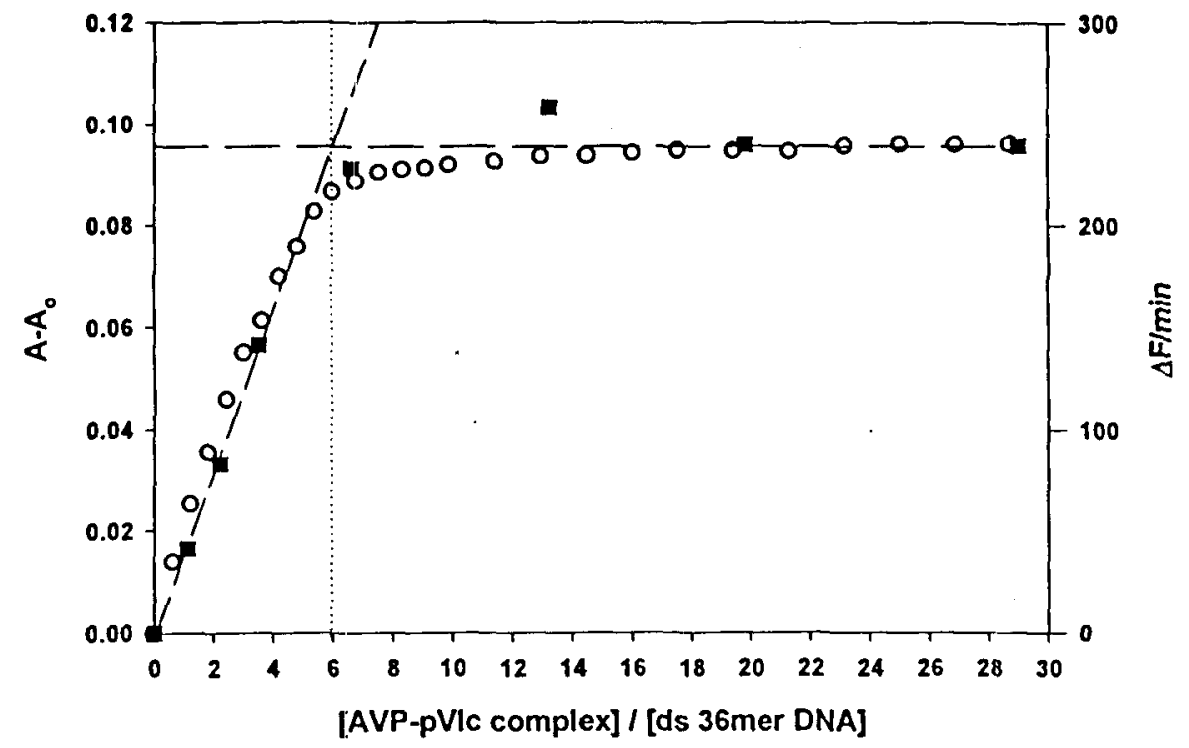

Fig. 2. Binding of the adenovirus proteinase (AVP)-pVIc complexes to DNA is coincident with stimulation of enzyme activity by DNA. AVP-pVIc complexes were formed by incubating a $1.5-\mathrm{M}$ excess of pVIc with AVP in $0.01 \mathrm{M}$ tris(hydroxymethyl)aminomethane (Tris, $\mathrm{pH} 8.0$ ), $5 \mathrm{mM} \mathrm{NaCl}$ and $1 \mathrm{mM}$ ethylenediaminetetraacetic acid (EDTA) on ice for $30 \mathrm{~min}$. Fluorescence anisotropy measurements (open circle) were performed with 12.5-nM 5'-fluorescein-labeled double-stranded (ds) 36mer DNA in $10 \mathrm{mM}$ Tris (pH 8.0), $0.1 \mathrm{mM}$ EDTA and $0.0125 \% \mathrm{NP}-40$ at $20^{\circ} \mathrm{C}$. Aliquots of AVP-pVIc complexes were added to the DNA; the solutions were mixed and, $30 \mathrm{~s}$ after each addition, the change in anisotropy $\left(A-A_{0}\right)$ was measured using an excitation wavelength of $490 \mathrm{~nm}$ and a $520-\mathrm{nm}$ bandpass filter. Activity measurements (closed square) were performed with the AVP-pVIc complex in the presence or absence of 12.5 -nM ds $36-\mathrm{mer}$ DNA. in $10 \mathrm{mM}$ Tris (pH 8.0 ), $5 \mathrm{mM}$ octylglucoside and $5 \mu \mathrm{M}$ (LeuArg-Gly-Gly-NH $)_{2}-$ Rhodamine at $20^{\circ} \mathrm{C}$. The change in fluorescence $(\Delta \mathrm{F})$ was monitored as a function of time using an excitation wavelength of $492 \mathrm{~nm}$ and an emission wavelength of $523 \mathrm{~nm}$. The units of the abscissa are moles of AVP-pVIc complex divided by moles of ds 36-mer DNA. The dashed lines are least-squares fits to the data points. The vertical dotted line defines the intersection of the two dashed lines at a molar ratio of 6

there was no unbound AVP-pVIc complex. Saturation, the intersection of the two straight lines, was achieved at 6 AVP-pVIc complexes per ds 36-mer DNA. If the experiment was repeated with fluorescein-labeled ds 36-mer DNA and if, instead of assaying for enzyme activity, the change in anisotropy was measured, the two curves were superimposable. These two sets of data indicate that the enzyme binds to DNA and that binding to DNA is coincident with enzyme stimulation.

\section{Roles of AVP Cofactors in Virus Maturation}

The functions of the cofactors might be to regulate the temporal and spatial activity of the enzyme (MANGEL et al. 1997). Our working hypothesis is that 
the enzyme is initially synthesized with negligible activity. Presumably, if it were active before virion assembly, it would cleave virion precursor proteins, thereby preventing virion assembly. Late in infection, virion proteins, including precursor proteins, assemble into "empty capsids" (BHATrI and WEBER 1978). Then the core proteins and AVP bound to the viral DNA are encapsidated, generating "young virions." Binding to DNA increases the $k_{\text {cat }}$ of AVP threefold. It is in these "top components" that the proteinase is activated and the precursor proteins are processed to yield mature, infectious virus. This could occur by pVI binding to the viral DNA (Russell and PrEcious 1982) such that AVP already bound to the viral DNA can excise pVIc. The released $p$ VIc could then bind AVP. The AVP-pVIc complex next binds to the viral DNA, and this ternary complex, AVP-pVIc-DNA, is a fully active proteinase.

How can 50 fully-activated proteinases (Brown et al. 1996) bound to the viral DNA inside the virion cleave 2500 peptide bonds in precursor proteins to render a virus particle infectious? Perhaps the viral DNA serves as a guidewire, next to which are the 2500 processing sites that must be cleaved. The proteinase complex could then slide along the viral DNA, cleaving the precursor proteins. The binding of AVP-pVIc complexes to DNA is not sequence specific (MANGEL et al. 1993), a property that allows the proteinase to move along the viral DNA. This would be analogous to the binding of the $E$. coli RNA polymerase holoenzyme to nonpromoter DNA sequences (Hinkle and Chamberlin 1972). RNA polymerase binds to nonpromoter DNA sequences with a $K_{\mathrm{d}}$ of $100 \mathrm{nM}$, and the polymerase slides along the DNA via one-dimensional diffusion (SINGER and Wu 1988) until it locates a promoter. In the case of AVP, it slides along the viral DNA, encountering precursor cleavage sites.

\section{Crystal Structure of the Adenovirus-2 Proteinase Complexed with pVIc}

The crystal structure of an AVP-pVIc complex has been solved to 2.6- $\AA$ resolution by means of $\mathrm{X}$-ray-crystallographic analysis using single isomorphous replacement supplemented with anomolous scattering (DiNG et al. 1996). The AVP-pVIc complex is ovoid, with $\alpha$-helices forming the wide end (Fig. 3). The narrow end contains another $\alpha$-helix, and the region between comprises one central and two peripheral $\alpha$-helices that interact with a $\beta$-sheet. The $\beta$-sheet consists of five $\beta$-strands from AVP; a sixth $\beta$-strand originates from the last eight amino-acid residues of pVIc.

AVP appears to represent a new type of proteinase. The sequence of the gene for the proteinase is not related to any gene sequences in the databases. Inhibitor profiles of enzyme activity give ambiguous results in revealing the type of proteinase. Comparing the structure of AVP-pVIc with all unique protein molecules in the Brookhaven Protein Data Bank (Bernstein et al. 


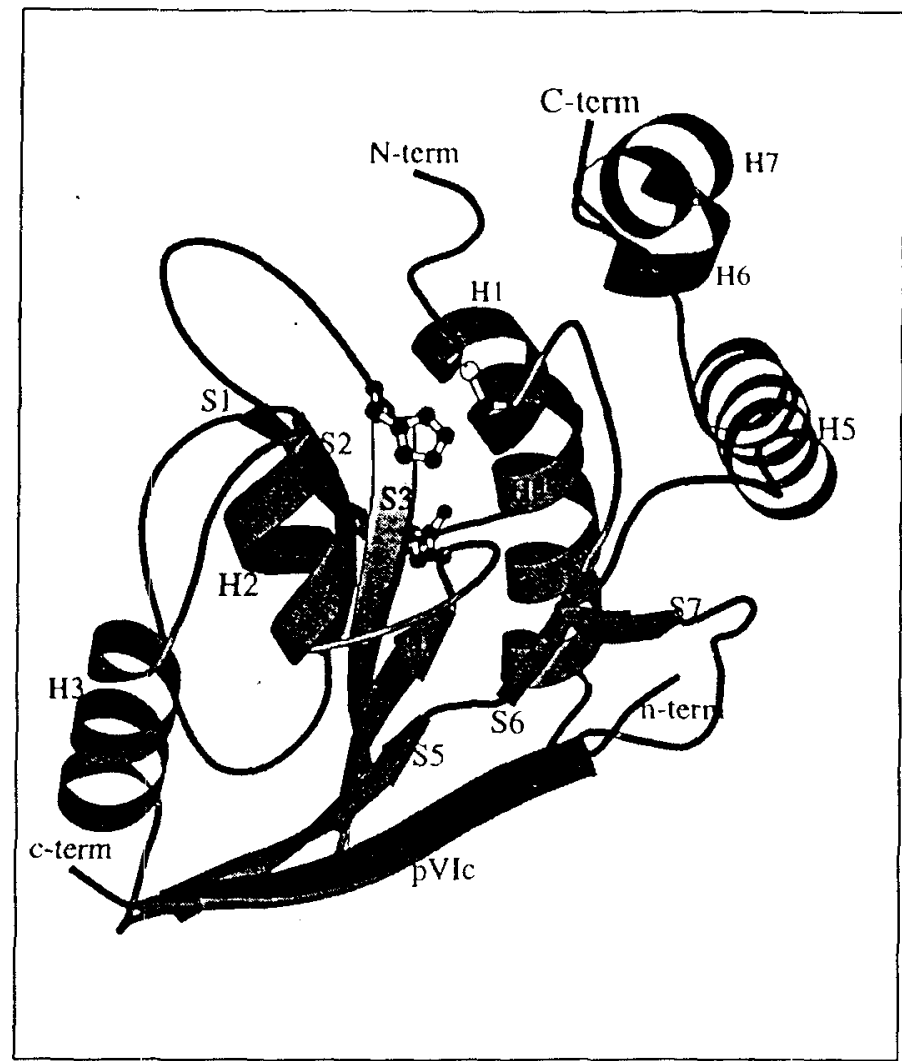

Fig. 3. The secondary structure of the adenovirus proteinase-pVIc complex. $\alpha$-Helices are labeled $\mathrm{H} 1$ through $\mathrm{H} 7 ; \beta$-strands $\mathrm{S} 1$ through $\mathrm{S} 7$ from the $\mathrm{N}$ - to $\mathrm{C}$-terminus. pVIc, is the nearest $\beta$-strand of the figure. Side chains are shown only for the active-site residues Cys122, Hisi54 and Glu71

1977) revealed no equivalent structure, suggesting that AVP represents a new family of protein molecules.

However, we noticed some structural similarities between papain and the AVP-pVIc complex; a helix and several $\beta$-strands within the central region of papain appear to be in similar positions in the AVP-pVIc complex. When we superimposed those structural similarities, we found that the nucleophilic Cys25 of papain superimposed over Cys 122 of AVP (Fig. 4, s. appendix, page 398/399). Furthermore, His159 and Asn175 of papain superimposed over His54 and Glu71 of AVP. Even the major component of the oxyanion hole, Gln19 of papain, superimposed over Gln115 of AVP. Thus, AVP is the first member of a new class of cysteine proteinases, C5 (RAwlings and BARRETr 1994); it is an example of convergent evolution. Despite the similarities with 
papain in the positions of the amino-acid residues involved in catalysis, the sequential order of these amino-acid residues in the polypeptide chain is different. In AVP, the triad involved in catalysis is His54, Glu71 and Cys122, whereas in papain the order is Cys25, His159 and Asn175.

\section{Potential Inhibitor-Binding Sites}

There are general "rational" and "irrational" ways to obtain inhibitors of AVP. One "rational" way is "structure-based drug design". This approach utilizes computer graphics to display the topography of a potential drug-binding site so that one can design drugs complementary to this site. A computer can be used both automatically and systematically to screen structurally diverse compounds for prototypes that fit. Searches of chemical data bases using the coordinates of AVP deposited in the Brookhaven Data Base (accession number 1AVP) via programs such as DOCK (KUNTZ 1992; SHolchet et al. 1992; Shoichet and KunTz 1993), CAVEAT (LAuri and Bartlett 1994) or SYSDOC, a supercomputing-based dimeric analog approach for drug optimization (PANG and Kollman 1995; PANG and BrimiJorn 1998), should aid in the identification of lead compounds. A general "irrational" approach to drug design is the "combinatorial-library" method. Here, many thousands of structurally diverse compounds are generated by combinatorial chemistry and the products evaluated with automated, high-throughput assays. Once a large number of active structures is ascertained, their common structural motifs are identified by deconvolution (LAM et al. 1997).

Lead compounds, identified "rationally" or "irrationally," are then refined to become even better inhibitors. First, one measures the inhibitory equilibrium dissociation constant, expecting it to be micromolar or lower. Then, the lead compound is co-crystallized with the enzyme. Are the contacts as predicted? Based upon the structure, a second generation inhibitor is designed, synthesized, tested and co-crystallized with the enzyme. The process is repeated until a selective inhibitor with a low equilibrium dissociation constant is obtained.

\section{Active Site}

The active site of AVP is on the surface of the molecule. It lies within a $25-\AA$ long, bent groove that is $\sim 8-\AA$ wide. Cys 122 and His 54 lie in the middle of the groove. There are several areas within the active site to which inhibitors can be designed to bind.

AVP is both different from and similar to papain, and this can be exploited in the design of unique inhibitors of AVP. For example, there are many different low-molecular-weight inhibitors of papain; their contacts within the active site of papain are known because they have been co-crystallized with papain and their structures determined by X-ray diffraction (KIM et al. 1992). Regions of papain where inhibitors bind can be compared with similar regions in $A V P$. Then, the inhibitors of papain can be redesigned to take into account 
the differences. For example, E-64 ( $N$-[ $N$-(L-3-trans-carboxirane-2-carbonyl)L-leucyll-agmatine) is an excellent inhibitor of papain that does not inhibit AVP (McGrath et al. 1996). One may be able to redesign E-64, retaining common contacts with papain and AVP, removing contacts unique to papain, and inserting contacts unique to AVP, such that the resultant compound becomes an inhibitor of AVP and not of papain.

There are several ways in which the substrate specificity of AVP can be exploited in inhibitor design. Competitive inhibitors can be substrate like. We know the specificity determinants in substrates for AVP are the P4 and P2 amino acids. Thus, compounds that reflect this specificity and have the potential to inhibit the enzyme can be designed, synthesized and tested. For example, these compounds could contain a nonhydrolyzable reduced peptide bond (Holskin et al. 1995), an aldehyde (MACKENZIE et al. 1986) or a monofluoroketone (RASNick 1985; McGrath et al. 1995) at the P1 position.

The substrate specificity of AVP can be taken advantage of to deliver specific inhibitors to the active-site groove. We have performed modeling studies using the five amino acids at the site in the virus-coded protein $\mathrm{pVI}$ where cleavage by AVP liberates pVIc-Ile-Val-Gly-Leu-Gly (Fig. 5, s. appendix, page 398/399). Energy-minimization studies indicate the substrate binds to the active-site groove as a $\beta$-strand. The $\mathrm{P} 2$ amino acid binds in a very small hydrophobic groove. The P4 amino acid binds in a larger pocket that can best accommodate a Leu, Ile or Met residue. The side chains of the P1 and P3 amino acids point away from the surface of AVP, which is why they are not specificity determinants. Thus, one can attach inhibitory groups to the P1 and/or P3 amino-acid side chains or even a putative P5 side chain, and the resultant peptide should still bind specifically in the active-site groove.

\section{DNA-Binding Sites}

We don't know where DNA binds on the surface of the AVP-pVIc complex. However, the molecular surface of the AVP-pVIc complex has four large clusters of positive-charge density ranging in area from $45 \AA^{2}$ to $65 \AA^{2}$; these are potential DNA-binding sites (Fig. 6, s. appendix, page 398/399). The shortest distance between clusters $(-24 \AA)$ is commensurate with the rise of a single turn of ds helical DNA. We are trying to obtain X-ray diffraction-quality crystals of an AVP-pVIc-DNA complex. Once the structures of the DNA-binding sites are known, compounds will be designed to bind to these sites. Although DNA binding is not sequence specific, the DNA-binding sites may be unique, and it is to these sites that specific inhibitors may be designed. Our presumption is that a compound is a potential antiviral agent if it prevents AVP from binding to the viral DNA.

\section{III. pVIc-Binding Sites}

The pVIc-binding site is another place inhibitory molecules may bind. Surprisingly, pVIc, which exerts powerful control over the rate of catalysis, binds 
quite far from the active-site residues involved in catalysis. The cysteine residue of pVIc forms a disulfide bond with Cys 104 of AVP, which is $32 \AA$ away from the active-site nucleophile Cys122. The residue of pVIc closest to the active site is Val2', whose side chain is $14.5 \AA$ away from Cys 122 . There is extensive contact between pVIc and AVP: 28 hydrogen bonds, 4 ionic bonds and a disulfide bond (Fig. 7, s. appendix, page 402/403). pVIc directly interacts with two different regions of AVP, and this suggests both how pVIc may increase $k_{\mathrm{cat}}$ and how to design potential proteinase inhibitors. pVIc appears as a "strap" that sparis a region from the conserved Cys104 near the narrow end of the structure across the back of the molecule, i.e., away from the active-site groove, to the turn at the end of helix 4 near the active-site groove. One possible function of pVIc may be that, upon binding, it brings two regions of AVP together: the formation of the $\beta$-sheet on one end of pVIc with the central $\beta$ structure of the molecule and the extensive contact of pVIc's amino-terminal region with residues that interact near the $\mathrm{C}$-terminal end of helix 4 . The functional consequences of bringing two regions of AVP together may be that this alters the geometry around the putative Cys-His ion pair, thereby increasing the pair's catalytic power. If $p$ VIc really functions as a strap, then molecules that prevent $\mathrm{pVIc}$ from bringing two regions of AVP together are potential proteinase inhibitors.

Different ligands that bind to the pVIc-binding site in AVP in preference to $\mathrm{pVIc}$ can have different effects. Some ligands may increase the $k_{\text {cat }}$ for substrate hydrolysis, like pVIc. The binding of other ligands may prevent the activation of AVP. Since we don't yet know how the binding of pVIc to AVP activates the enzyme, we cannot predict whether a specific ligand will stimulate or prevent the activation of the enzyme. However, both types of ligands may be antiviral agents. A ligand that stimulates the activation of AVP could be used to activate AVP before virion assembly. Then, that complex would cleave virion precursor proteins, thereby preventing the formation of nascent virus particles. Alternatively, the ligand that prevents activation of AVP would prevent maturation of precursor proteins within virions, thus preventing the virus particle from becoming infectious.

If $\vec{p} V I c$ is a "strap" that holds together two domains of AVP, then peptides that interfere with the binding of native pVIc and prevent a "strap" from forming should inhibit the activation of AVP. For example, the $\mathrm{N}$ - and $\mathrm{C}$ terminal amino-acid residues of pVIc - GVQ and SLKRRRCF, respectively - should bind to AVP. Although GVQ should bind to the C-terminal end of helix 4 , binding alone it should not be able to bring both domains together. Similarly, although SLKRRRCF may be able to form a $\beta$-strand with the central $\beta$-sheet structure, binding alone it should not be able to bring that domain closer to the $C$-terminal end of helix 4.

Another potential inhibitor is the peptide GVAALAARACA. It is a mutant in which the amino-acid residues of $p$ VIc whose side chains interact with AVP have been replaced by an alanine residue. Side-chain interactions are very specific, possibly more so than the interactions of AVP with the 
peptide backbone of $\mathrm{pVIc}$. This mutant peptide may prevent a series of subtle positional changes throughout the AVP-pVIc complex that result in the 350fold increase in enzyme activity.

The crystal structure of the AVP-pVIc complex revealed that amino-acid residues $3^{\prime}, 7^{\prime}, 9^{\prime}$ and $11^{\prime}$ in pVIc form salt bridges with AVP. Thus, GVASLKARAC is a peptide that should not be able to form any of the salt bridges with AVP. Testing of this mutant will show whether the salt bridges are required for pVIc stimulation of enzyme activity. If they are required, then additional experiments can be done to determine which salt bridges are important. This approach may lead to an abbreviated form of pVIc that can stimulate enzyme activity.

\section{E. Summary and Prospects}

Human adenovirus is a good model system with which to study the exploitation of virus-coded proteinases as targets for antiviral therapy. Because activation of AVP utilizes two cofactors, the viral DNA and the 11-amino-acid peptide pVIc, this is a good model system with which to test the hypothesis that the probability of generating a virus resistant to three different inhibitors directed against three different sites in the same virus-coded protein is much lower than to three different inhibitors directed against three different viruscoded proteins. Once we have compounds that inhibit the enzyme in vitro, we shall test them with viruses and cells in culture. A wide range of animals, including mice, chickens and monkeys, can be infected with different strains of adenovirus so that we can test the more promising inhibitors in several animal systems.

Although we present human adenovirus as a model system within which to study the use of proteinase inhibitors as antiviral agents, the results of our experiments are directly applicable to other medically important proteinases, because human adenovirus is "less unique" than it used to be. The Sindbis virus serine proteinase has a very basic $\mathrm{N}$-terminal segment responsible for association with the viral RNA (ToNG et al. 1993). The NS3 protein of hepatitis-C virus is a serine proteinase whose activity is enhanced by a cofactor, the 54amino-acid residue NS4A protein. A 12-residue synthetic peptide, comprising amino acids 12-33 of NS4A, forms a complex with the NS3 proteinase domain and activates the enzyme so that it can cleave at certain processing sites (ButKIEwICZ et al. 1996; KIM et al. 1996).

There are numerous sites on AVP where ligands can bind and, in doing so, should inhibit enzyme activity. Within the active site, there are several different regions. The DNA-binding site will soon be revealed, and polyanions designed to bind to it should be good antiviral agents. Although we still don't know how the binding of pVIc to AVP increases $k_{\text {cat }}$ for substrate hydrolysis, we do know how pVIc binds to AVP; this has enabled us to design several potential antiviral agents. 
Acknowledgements. The research was supported by National Institute of Allergy and Infectious Diseases Grant Al41599, the Office of Health and Environmental Research of the United States Department of Energy, the National Science Foundation and the Department of Energy's Office of Science Education and Technical Information. The work on testing pVIc as an antiviral agent on virus-infected cells in culture was funded by Contract N01-AI-35178 from the Virology Branch, Division of Microbiology and Infectious Diseases, National Institute of Allergy and Infectious Diseases (NIAID), National Institutes of Health. We also thank S. Klein and M. Garner for help with the manuscript.

\section{References}

Anderson CW (1993) Expression and purification of the adenovirus proteinase polypeptide and of a synthetic proteinase substrate. Protein Expr Purif 4:8-15

Bebé LM, Craig CS (1997) Viral proteases: evolution of diverse structural motifs to optimize function. Cell 91:427-430

Bernstein FC, Koetzle TF, Williams, GJB, Meyer EF, Brice MD, Rodgers JR, Kennard O, Shimanouchi T, Tasumi M (1977) The protein data bank: A computer-based archival file for macromolecular structure. J Mol Biol 112:535-542

Bhatti AR, Weber J (1978) Protease of adenovirus type 2. In vitro processing of core protein. Biochem Biophys Res Commun 81:973-979

Brown MT, McGra.th WJ, Toledo DL, Mangel WF (1996) Different modes of inhibition of human adenovirus proteinase, probably a cysteine proteinase, by bovine pancreatic trypsin inhibitor. FEBS Lett 388:233-237

Butkiewicz NJ, Wendel M, Zhang R, Jubin R, Pichardo J, Smith EB, Hart AM, Ingram R, Durkin J, Mui PW, Murray MG, Ramanathan L, Dasmahapatra B (1996) Enhancement of hepatitis C virus NS3 proteinase activity by association with NS4A-specific synthetic peptides: identification of sequence and critical residues of NS4A for the cofactor activity. Virology 225:328-338

Cotten M, Weber J (1985) The adenovirus protease is required for virus entry into host cells. Virology 213:494-502

Ding J, McGrath WJ, Sweet RM, Mangel WF (1996) Crystal structure of the human adenovirus proteinase with its 11 amino-acid cofactor. EMBO J 15:17781783

Greber UF, Webster P, Weber J, Helenius A (1996) The role of the adenovirus protease in virứ êntry iñto cells. EMBO J 15:176́-1777

Hannan C, Raptis LH, Dery CV, Weber J (1983) Biological and structural studies with adenovirus type 2 temperature-sensitive mutant defective for uncoating. Intervirology 19:213--223

Hinkle D, Chamberlin M (1972) Studies of the binding of E. coli RNA polymerase to DNA. II. The kinetics of the binding reaction. J Mol Biol 70:187-196

Hierholzer JC, Stone YO, Broderson JR (1991) Antigenic relationships among the 47 human adenoviruses determined in reference horse antisera. Arch Virol 121:179-197

Holskin BP, Bukhtiyarova M, Dunn BM, Baur P, de Chastonay J, Pennington MW (1995) A continuous fluorescence-based assay of human cytomegalovirus protease using a peptide substrate. Anal Biochem 226:148-155

Horwitz MS (1990) Adenoviruses. In: Fields BN, Knipe DM (eds) Fields' virology (vol 2), 2nd edn. Raven, New York, pp 1723-i742

Kim M-J, Yamamoto D, Matsumoto K, Inoue M, Ishida T, Mizuno H, Sumiya $S$, Kitamura K (1992) Crystal structure of papain-E64-c complex: binding diversity of E64-c to papain S2 and S3 subsites. Biochem J 287:797-803

Kim JL, Morgenstern KA, Lin C, Fox T, Dwyer MD, Landro JA, Chambers SP, Markland W, Lepre CA, O'Malley ET, Maberson SL, Rici CM, Murcko MA, 
Caron PR, Thomson JA (1996) Crystal structure of the hepatitis C virus NS3 protease domain complexed with a synthetic NS4A peptide cofactor. Cell 87:343-355

Krausslich H-G, Wimmer E (1998) Vital proteinases. Annu Rev Biochem 57:701754

Kuntz ID (1992) Structure-based strategies for drug design and discovery. Science 257:1078-1082

Lam KS, Lebl M, Krchnak V (1997) The "one bead-one compound" combinatorial library method. Chem Rev 97:411

Lauri G, Bartlett PA (1994) A program to facilitate the design of organic molecules. J Comput Aided Mol Des 8:51-66

Mackenzie NE, Grant SK, Scott AI, Malthouse PG (1986) ${ }^{13}$ C NMR study of the stereospecificity of the thiohemiacetals formed on inhibition of papain by specific enantiomeric aldehydes. Biochemistry 25:2293-2298

Mangel WF, McGrath WJ, Toledo DL, Anderson CW (1993) Viral DNA and a viral peptide can act as cofactors of adenovirus virion proteinase activity. Nature 361:274-275

Mangel WF, Toledo DL, Brown MT, Martin JH, McGrath WJ (1996) Characterization of three components of human adenovirus proteinase activity in vitro. $\mathrm{J}$ Biol Chem 271:536-543

Mangel WF, Toledo DL, Ding J, Sweet RM, McGrath WJ (1997) Temporal and spatial control of the adenovirus proteinase by both a peptide and the viral DNA. Trends Biochem Sci 22:393-398

McGrath ME, Eakin A.E, Engel JC, McKerrow JH, Craik CS, Fletterick RJ (1995) The crystal structure of cruzain: a therapeutic target for Chagas' disease. J Mol Biol 247:251-259

McGrath WJ, Abola AP, Toledo DL, Brown MT, Mangel WF (1996) Characterization of human adenovirus proteinase activity in disrupted virus particles. Virology 217:131-138

Mirza A, Weber J (1980) Infectivity and uncoating of adenovirus cores. Intervirology 13:307-311

Pang Y-P, Kollman PA (1995) Applications of free energy derivatives to analog design. Perspect Drug Discov Des 3:106-122

Pang Y-P, Brimijoin S (1998) Supercomputing-based dimeric analog approach for drug optimization. Parallel Computing 24:1557-1566

Rasnick D (1985) Synthesis of peptide fluoromethylketones and the inhibition of human cathepsin B. Anal Biochem 149:461-465

Rawlings ND, Barrett AJ (1994) Families of cysteine peptidases. Meth Enzymol 244:461-486

Russell WC, Precious B (1982) Nucleic acid-binding properties of adenovirus structural polypeptides. J Gen Virol 63:69-79

Schechter I, Berger A (1967) On the size of the active site in proteases. I. Papain. Biochem Biophys Res Commun 27:157-162

Shoichet BK, Bodian DL, Kuntz ID (1992) Molecular docking using shape descriptors. J Comp Chem 13:380-397

Shoichet BK, Kuntz ID (1993) Matching chemistry and shape in molecular docking. Protein Eng 6:723-732

Singer PT, Wu C-W (1988) Kinetics of promoter search by Escherichia coli RNA polymerase: effets of monovalent and divalent cations and temperature. J Biol Chem 263:4208-4214

Tihanyi K, Bourbonniere M, Houde A, Rancourt C, Weber J M (1993) Isolation and properties of adenovirus type 2 proteinase. J Biol Chem 268:1780-1785

Tong L, Wengler G, Rossmann MG (1993) Refined structure of Sindbis virus core protein and comparison with other chymotrypsin-like serine proteinase structures. J Mol Biol 230:228-247

Webster A, Russell S, Talbot P, Russell WC, Kemp GD (1989a) Characterization of the adenovirus proteinase: substrate specificity. J Gen Virol 70:3225--3234 
Webster A, Russell W C, Kemp GD (1989b) Characterization of the adenovirus proteinase; development and use of a specific peptide assay. J Gen Virol 70: 32153223

Webster A, Hay RT, Kemp G (1993) The adenovirus protease is activated by a viruscoded disulphide-linked peptide. Cell 72:97-104

Yeh-Kai L, Akusjarvi G, Alestrom P, Petterson U, Tremblay M, Weber J (1983) Genetic identification of an endopeptidase encoded by the adenovirus genome. J Mol Biol $167: 217-222$ 
1 Fig. 3, Chapter 5: Solvent-accessible surface of NS3 proteinase with a modeled substrate (AspGluMetGluGluCys-AlaSerHisLeu). Hydrophobic areas on the protein surface are coloured in yellow, basic areas are in blue and acidic areas are in red. The solvent-accessible surface area of NS4A is shown in magenta

2 Fig. 4, Chapter 5: Ribbon representation of the X-ray structure of NS3 proteinase with the NS4A cofactor in red. Also shown, with green carbon atoms, is the backbone of a modeled product inhibitor. Hydrogen bonds by $P_{3}$ and $P_{5}$ are indicated as dashed lines. The carbon atoms of the catalytic triad are shown in yellow

3 Fig. 5, Chapter 8: Modeling of a substrate in the active site. The Connolly surface of the adenovirus proteinase-pVIc complex, in pink, is shown with the putative active-site residues, colored orange. The substrate, in Corey-Pauling-Koltun-model form, has the sequence Ala-Ala-Ile-Val-Gly-Leu-Gly-Val; cleavage occurs at the Leu-Gly bond. The side chains of the P1-P4 amino-acid residues are labeled

4 Fig. 4, Chapter 8: Juxtaposition of the active-site residues of papain with equivalent residues of the adenovirus proteinase (AVP)-pVIc complex. The residues involved in catalysis in papain are shown after alignment of the papain molecule to fit the equivalent residues in AVP-pVIc. For papain, the active-site residues are shown with the carbon atoms colored magenta; for the AVP-pVIc complex, the carbon atoms are colored green. For both molecules, the nitrogens are colored blue and the oxygens red. The important bond distances (in $\AA$ ) are shown by dashed magenta lines for papain and dashed green lines for AVP-pVIc

5 Fig. 6, Chapter 8: Possible DNA-binding sites on the adenovirus proteinase (AVP)-pVIc complex. The charge-potential map of the distribution of positive (blue) and negative ( $r e d$ ) charges on the surface of the AVP-pVIc complex is shown

6 Fig. 7, Chapter 8: Binding interactions between pVIc and adenovirus proteinase (AVP). The dashed lines from atoms of pVIc, which is in ball-and-stick form, indicate the sites of interaction between pVIc and AVP. Hydrogen bonds are represented by dashed lines; dashed yellow lines represent $\mathrm{pVIc}$ side chain interactions with AVP and dashed magenta lines represent the backbone atoms of the $\beta$-sheet of pVIc with AVP. The disulfide bond between Cys10' of pVIc and Cys104 of AVP is in green. Water molecules are represented by blue spheres 

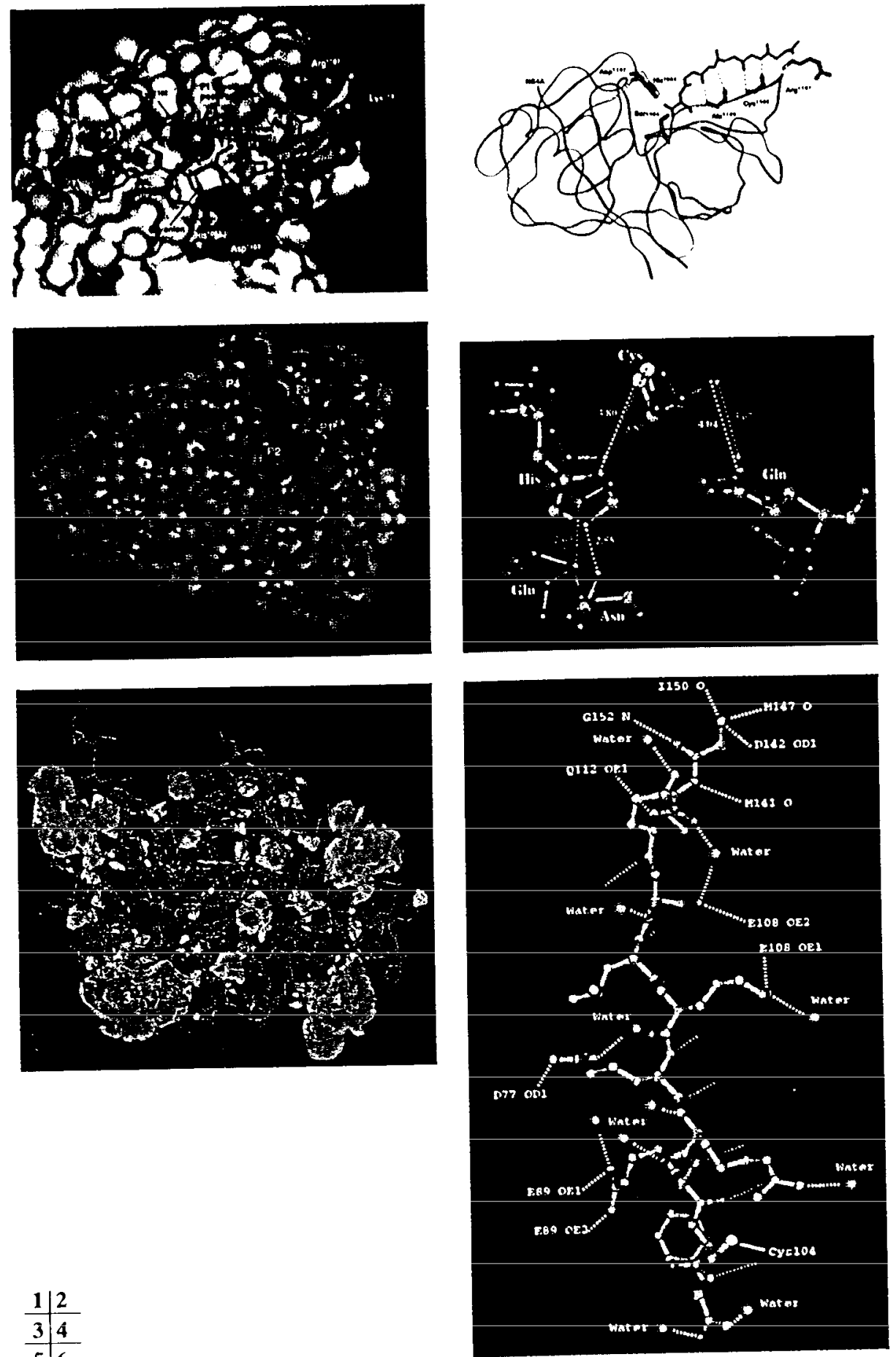

\begin{tabular}{l|l}
1 & 2 \\
\hline 3 & 4 \\
\hline 5 & 6
\end{tabular} 